Chanjan Documet, Rafael H. "Repercusiones jurídicopenales del criminal compliance. A propósito de la regulación española", Nuevo Foro Penal, 95, (2020).

\title{
Repercusiones jurídico-penales del criminal compliance. A propósito de la regulación española
}

\section{"Legal-criminal repercussions of criminal compliance. About Spanish regulation"}

Rafael H. Chanjan Documet*

Fecha de recepción: 08/07/2020. Fecha de aceptación: 07/09/2020

DOI: 10.17230/nfp16.95.5

\section{Resumen}

El presente trabajo estudia el paradigma del compliance desde un punto de vista jurídico-penal a fin de evaluar las implicancias que generan en la determinación de la responsabilidad penal individual y de las personas jurídicas en el marco de la criminalidad empresarial. En tal sentido, esta investigación se aproxima al fenómeno de la autorregulación como nueva estrategia político-criminal para prevenir delitos en las sociedades, siendo el criminal compliance una de las manifestaciones más ejemplificativas de una autorregulación regulada que pretende coadyuvar a las labores

* Docente de Derecho Penal de la Pontificia Universidad Católica del Perú (PUCP). Doctorando en Derecho por la Universidad de Murcia (España). Máster en Derecho Penal y Política Criminal por la Universidad de Málaga (España). Máster en Derecho Penal Económico Internacional por la Universidad de Granada (España). Docente de Transparencia Internacional (Venezuela). Coordinador del Proyecto Anticorrupción del Instituto de Democracia y Derechos Humanos de la PUCP. Miembro Grupo de Investigación en Derecho Penal y Corrupción (DEPEC) de la PUCP. Correo electrónico: rchanjan@ pucp.pe. 
138 Repercusiones jurídico-penales del criminal compliance. A propósito de la regulación española - Rafael H. Chanjan Documet,

estatales de detección, investigación y prevención del delito. Definitivamente, uno de los ámbitos en los que mayor importancia tiene el nuevo paradigma del compliance es en el de la responsabilidad penal de las personas jurídicas, aunque también se reconoce su influencia en la determinación de las responsabilidades individuales en el marco de actividades organizacionales.

\section{Abstract}

This paper studies the paradigm of compliance and self-regulation from a legal-criminal point of view in order to assess the implications they generate in the determination of criminal liability of individual and legal persons within the framework of the corporate crime. In this sense, this research approaches the phenomenon of self-regulation as a new strategy of the criminal policy to prevent crimes in societies, with criminal compliance being one of the most exemplary manifestations of a regulated selfregulation that aims to assist state crime detection, investigation and prevention. Definitely, one of the areas in which the new paradigm of compliance is most important is the criminal liability of legal persons, although its influence is also recognized in determining individual responsibilities in organizational activities.

\section{Palabras clave}

Criminal compliance - autorregulación - responsabilidad penal de las personas jurídicas - criminalidad de empresa

\section{Keywords}

Criminal compliance - self-regulation - criminal liability of legal persons - corporate criminality

\section{Sumario}

1. Introducción: fundamentos y ventajas de laautorregulaciónempresarial. 2.Compliance y Derecho Penal: Criminal Compliance. 3. Criminal compliance y responsabilidad penal de las personas jurídicas. 4. Criminal compliance y responsabilidad penal individual. $\mathbf{5}$. Conclusiones. Bibliografía.

\section{Introducción: fundamentos y ventajas de la autorregulación empresarial}

Tradicionalmente, se sostiene que la función de regular jurídicamente las diversas relaciones sociales corresponde al Estado. Ello aplicado a la actualidad 
podría generar una controversia sobre nuestra sociedad catalogada como la "sociedad de riesgo", pues los riesgos sociales, políticos, económicos e industriales cada vez escapan en mayor medida a las acciones estatales. Por tal motivo, nace el fenómeno de la "autorregulación", toda vez que el Estado posee una intervención y capacidad limitada en regulares actividades sociales altamente especializadas, como la actividad empresarial privada'.

En efecto, un componente importante para regular actividades altamente especializadas es el "conocimiento" del riesgo de actividad de cada entidad, lo cual es adquirido principalmente por la propia experiencia empresarial privada durante su funcionamiento ${ }^{2}$. Dando como resultado la necesidad de contar con mecanismos como la autorregulación por cada actor social, adoptando un modelo de "derecho regulador" por parte del Estado y dejando de lado el "derecho intervencionista" 3.

Adoptar este mecanismo autorregulador a nivel estatal ha sido influenciado por instrumentos y pronunciamientos de la comunidad internacional como los informes de la Organización para la Cooperación y el Desarrollo Económico (OCDE) en la mejora de calidad de servicios ${ }^{4}$.

Son diversas las ventajas de la autorregulación: primero, en actividades altamente complejas y tecnificadas que requieren un conocimiento técnico amplio y experiencia práctica, la autorregulación por los propios actores o agentes sociales propicia una mejor regulación de sus actividades ${ }^{5}$.

Segundo, se ha reconocido que en la medida que los códigos de conducta internos guardan relación con los valores éticos en las dinámicas empresariales, este tipo de autorregulaciones es útil para garantizar que los directivos y empleados cumplan con la ley. La autorregulación, entonces, serviría para que, a través de

1 B. FeıJóo SÁnchez. "Autorregulación y Derecho penal de la empresa: ¿una cuestión de responsabilidad individual?". En Autorregulación y sanciones, coordinado por L. Arroyo Jimenez Y A. Nieto Martin (Navarra: Aranzadi, 2015), 200.

2 Gomez-Jara Díez. "La incidencia de la autorregulación en el debate legislativo y doctrinal actual sobre la responsabilidad penal de las personas jurídicas", 253.

3 A. Nieto Martín. "Lección II. Cumplimiento normativo, criminología y responsabilidad penal de personas jurídicas", En Manual de cumplimiento penal, coordinado por A. Nieto Martin. (Valencia: Tirant lo blanch, 2015), 258.

4 Recomendaciones del Consejo de la OCDE sobre la mejora de la calidad en la regulación estatal, de 9 de marzo de 1995; Reporte de la OCDE sobre las reformas regulatorias, de 15 de junio de 1997; y La Guía de la OCDE sobre principios para la calidad regulatoria, de abril de 2005.

5 A. Nieto Martín. "Responsabilidad social, gobierno corporativo y autorregulación: sus influencias en el derecho penal de la empresa". Política Criminal. n 5 (2008): 4. 
los códigos de ética, las corporaciones puedan ser más respetuosas del derecho estatal $^{6}$. Por ejemplo, el tener un protocolo interno sobre integridad y lucha contra la corrupción.

Tercero, el mecanismo de autorregulación sirve para mejorar los sistemas de información entre los miembros de la organización y, también, con personas y entidades externas?. Una de las manifestaciones más importantes de este sistema de información es la instauración y funcionamiento adecuado de canales de denuncia, el denominado whistleblowing. A fin de tener su propio material probatorio ante la detección de una infracción normativa y dar la información a las autoridades estatales.

Finalmente, la autorregulación fomenta la modificación estructural empresarial para crear nuevos órganos y designar personal encargado del cumplimiento normativo ${ }^{8}$. Es decir, la autorregulación implica a los directivos a la efectivización del debido control y supervisión de las actividades corporativas mediante la designación de oficiales de cumplimiento, auditores internos y externos, consejeros, etc.

Por otro lado, la doctrina ha realizado diversas clasificaciones del mecanismo de autorregulación. Así, se identifica a la autorregulación pura o voluntaria, la metaregulación y la autorregulación regulada o co-rregulación?

La autorregulación pura o voluntaria presupone la capacidad de las personas físicas y/o jurídicas de autosometerse a sus propias reglas, como la celebración de contratos, y se caracteriza porque la propia empresa crea un sistema de regulación interno absolutamente al margen de los poderes públicos (v. gr. Códigos éticos internos). Un tipo de autorregulación no directa con la regulación estatal ni en su creación ni en su implementación ${ }^{10}$

Por su parte, la meta-regulación consiste en el control ex ante o ex post de la actividad de autorregulación. El Estado interviene estableciendo una serie de reglas generales para que la propia organización se regule, con incentivos a los actores privados del Estado. Así, se fija parámetros mínimos a través de principios y normas generales abstractas para que las empresas establezcan su cuerpo normativo en

$6 \quad$ Ibid, 6.

7 Idem.

$8 \quad$ Ibid, 7.

9 Una clasificación distinta es la que realizan I. Bartle y P. Vass, quienes distinguen entre autorregulación vinculante o no vinculante [ARroyo Jimenez. "Introducción a la autorregulación", En Autorregulación y sanciones, coordinado por L. Arroyo Jimenez y A. Nieto Martin. (Navarra: Aranzadi, 2015) 34].

10 I. Coca VILA. "¿Programas de cumplimiento como forma de autorregulación regulada?" En Criminalidad de empresa y compliance, coordinado por Jesús María Silva Sánchez (Barcelona: Atelier, 2013) 48-49. 
función de su concreta situación ${ }^{11}$.

Por último, la autorregulación regulada o corregulación (enforced self-regulation) supone la incorporación del organismo privado en el proceso de regulación, pero desde una posición subordinada a las finalidades públicas determinadas por el Estado. Hay una colaboración entre Estado y empresa en el proceso de elaboración de cuerpos normativos, aunque con más intervención estatal. Precisamente, como veremos a continuación, este tipo de autorregulación sería el usado en materia de responsabilidad penal de las personas jurídicas, ya que el Estado regula y da ciertos efectos jurídicos a la creación e implementación de los compliance programs por parte de las organizaciones privadas ${ }^{12}$.

En sentido amplio, la "autorregulación regulada" son todas las manifestaciones de autorregulación sujetas a algún tipo de intervención pública. Desde este punto de vista, casi toda autorregulación sería regulada, pues siempre habrá algún grado de condicionamiento estatal directo o indirecto. Serían manifestaciones de autorregulación regulada los códigos éticos, normas técnicas, códigos y manuales de buenas prácticas, entre otros. Además, la autorregulación regulada no supone una renuncia del Estado de su función de satisfacer los intereses generales público. No se considera a la actividad como una tarea estatal, pero mantiene la condición de interés público ${ }^{13}$.

La finalidad ulterior de la regulación estatal en este mecanismo es el respeto de estándares, principios o parámetros mínimos procedentes del derecho público. Aspectos que guardan relación con las disposiciones normativas de la Constitución y tratados internacionales, a fin de asegurar derechos fundamentales de la persona y garantizar principios y reglas en el marco de un Estado social y Democrático de Derecho. Así como la tutela jurisdiccional efectiva y el principio de legalidad sancionadora ${ }^{14}$.

En ese sentido, el Estado establece algunos requisitos mínimos de la actuación regulatoria privada, estableciendo algunos aspectos procedimentales respecto de la adopción de decisiones de los privados, o atribuyendo a la autorregulación consecuencias jurídicas favorables o desfavorables. El sistema de responsabilidad penal de personas jurídicas se relaciona con la "autorregulación regulada", dado

\footnotetext{
11 Ibid, 50.

12 Ibid., 51.

13 Arroyo Jimenez. "Introducción a la autorregulación", 31-32.

14 Ibid., 38-41.
} 
que la exención 0 atenuación de la pena a las personas jurídicas por la adopción adecuada de compliance podría ser considerada como una consecuencia jurídica -estatal- "favorable" que fomenta la autorregulación en aras de la prevención de delitos y protección de bienes jurídico-penales. El Estado busca, de esta forma, "fomentar" la adopción e implementación de compliance empresariales para la prevención delictiva ${ }^{15}$.

\section{Compliance y Derecho Penal: Criminal Compliance}

Compliance hace referencia a "cumplimiento" o "conformidad"; es decir, el cumplimiento o conformidad con el Derecho. El compliance se puede describir como las medidas internas que adopta cierta organización para regular sus procesos y estructura con la finalidad de asegurar el cumplimiento de las normas o fidelidad al derecho ${ }^{16}$. Es decir, las medidas de prevención para asegurar tanto el cumplimiento de las normas aplicables a la misma y a sus trabajadores, como la denuncia y eventual sanción de sus infracciones ${ }^{17}$.

La obligatoriedad de los compliance se remonta al Foreign Corrupt Practices Act (FCPA) de 1977 en los Estados Unidos; normativa que buscó sancionar los actos de corrupción a funcionarios públicos extranjeros cometidos por empresas norteamericanas, como el caso "Watergate" en 1972 durante el mandato de Richard Nixon ${ }^{18}$. Este fue el primer contacto relacional entre la corrupción y el compliance. Aunque la real expansión de este mecanismo se dio a partir de los atentados del 11 de setiembre de 2001, cuando se aprobó el Patriot Act, que buscó implementar medidas contra el lavado de activos y el financiamiento del terrorismo, como la exigencia a las implementar programas de cumplimiento a las agencias financieras. Esta obligación fue reiterada en el Dood-Frank Wall Street Reform and Consumer Preotection Act de $2010^{19}$.

15 Darnaculleta I Gardella. "La autorregulación regulada en la doctrina anglosajona y continentaleuropea", 64.

16 D. Bock. "Compliance y deberes de vigilancia en la empresa". En Compliance y teoría del Derecho Penal, coordinado por J.P. Montiel, L. Kuhlen e I. Ortiz De Urbina Gimeno (Madrid: Marcial Pons, 2013), 107.

17 F. Balcarce y R. Berruezo. Criminal compliance y personas jurídicas. (Montevideo: BdeF, 2016), 140.

18 D.C. Caro Coria y L. M. Reyna Alfaro. Derecho Penal económico. Parte General. Tomo I. (Lima: Jurista Editores, 2016), 778.

19 P. García Cavero. Criminal compliance. En especial compliance anticorrupción y antilavado de activos. (Lima: Instituto Pacífico, 2017), 26-27. 
En Europa, los compliance tuvieron su apogeo en la crisis económica del 2007, originados por irregularidades en el sector privado, como los mercados financieros ajenos a una regulación estatal suficiente. Así, en la Unión Europea, se publicó la Directiva 2007/36/CE "de derechos de los accionistas para proteger al inversor, impulsar su participación en las juntas y mejorar el gobierno de las compañías", a fin de que los Estados fomenten el compromiso de las organizaciones privadas en la protección de economía. Esto generó que, en el 2010, España introdujera por primera vez el sistema de responsabilidad penal autónoma de personas jurídicas mediante L0 5/2010, fomentando la utilización de los compliance en las empresas.

En términos generales, los sistemas de compliance tienen dos finalidades que promueven en las organizaciones medidas diferenciadas. Por un lado, la "función de prevención" generará la adopción de medidas de vigilancia y supervisión dentro de la empresa. Para ello, se considerará llevar a cabo una prevención situacional de los ilícitos, a efectos de modificar los factores ambientales que propician su aparición. Se busca impedir los riesgos empresariales neutralizando su fuente y evitando la afectación de bienes jurídicos de terceros. Por otro lado, la "función de confirmación del derecho" supondrá la adopción de mecanismos confiables y seguros para la detección interna, investigación y denuncia de ilícitos cometidos dentro de la empresa ${ }^{20}$.

Ahora bien, el compliance es una institución que no se vincula necesariamente a los mandatos y prohibiciones jurídico-penales, al contrario, se ha mostrado que los programas de cumplimiento son de aplicación para prevenir una diversidad de ilícitos, pues es una manifestación del denominado "buen gobierno corporativo". El derecho penal es la última rama del derecho en acoger esta figura, toda vez que fue trasladada del derecho corporativo.

El criminal compliace es una manifestación específica de los programas de cumplimiento que previene delitos en las organizaciones; pretende que los miembros de la empresa se comparten conforme al Derecho Penal, evitando -asíla responsabilidad penal de ellos y la propia empresa ${ }^{21}$. De manera específica, por criminal compliance o compliance penal se identifica al compliance que busca garantizar que los miembros de una organización cumplan con los mandatos y prohibiciones jurídico-penales y en caso se cometa sea posible su descubrimiento, investigación y sanción22. En otras palabras, es una manifestación específica de

20 P. García Cavero. Criminal compliance. En especial compliance anticorrupción y antilavado de activos, 33.

21 CFr. T. Rotsch, "Criminal compliance". Indret, 1/2012 (2012). 5 y ss.

22 CocA VILA, “iProgramas de cumplimiento como forma de autorregulación regulada?”, 54-55. 
los programas de cumplimiento que se dedica a la prevención de delitos en las organizaciones.

\section{Criminal compliance y responsabilidad penal de las personas jurídicas}

Actualmente, algunos países de tradición jurídica continental con sistemas de responsabilidad penal autónoma de personas jurídicas contemplan la figura del criminal compliance: i) como mecanismo de prevención de ilícitos y ii) como eximente de responsabilidad penal para las organizaciones. Estos Estados utilizan las disposiciones penales para incentivar a las organizaciones a adoptar un criminal compliance. Por ejemplo, en España y Perú, estos programas han sido usados para la prevención de delitos como los de corrupción o delitos contra la administración pública. Cuestión similar ha sucedido en Argentina ${ }^{23}$ y Chile ${ }^{24}$.

El caso de España es particular, pues la responsabilidad penal autónoma de las personas jurídicas regulada en el artículo 31bis de su Código Penal se aplica para una pluralidad extensa de delitos tales como el tráfico ilegal de órganos humanos, trata de seres humanos, estafas, insolvencias punibles, fraude tributario, delitos contra la propiedad intelectual, blanqueo de capitales, delitos contra la salud pública, ciertos delitos contra la administración pública, terrorismo, contrabando, etc.

En efecto, en el caso de este país, se tiene un sistema de autorresponsabilidad penal (o responsabilidad autónoma) de las personas jurídicas desde la reforma de $2015^{25}$ y se regula como una eximente de responsabilidad penal la implementación de un criminal compliance. Aunque se requieren dos tipos de requisitos ligeramente

23 Este sistema se instauró recientemente en diciembre de 2017 a través de la Ley 27.401 para delitos de cohecho y tráfico de influencias (nacional y trasnacional), negociaciones incompatibles con el ejercicio de funciones públicas, concusión, enriquecimiento ilícito de funcionarios y empleados y presentación de informes y balances falsos.

24 La Ley 21.121 de noviembre de 2018 amplió los delitos que generan responsabilidad penal de las personas jurídicas a los delitos de soborno nacional y transnacional, apropiación indebida, negociación incompatible, los nuevos delitos de corrupción entre particulares, el tráfico de influencias entre particulares y la administración desleal.

25 Regulado por el artículo 31bis del Código Penal Español que indica como una eximente contar con un criminalcompliance. Al respecto, cabe reconocer que exuisten algunos autores ibéricos que consideran que no se trata de un sistema de autorresponsbilidad, sino vicarial o de heterorresposabilidad. Así por ejemplo, Cfr. M. Cugar Mauri, "La reforma de la responsabilidad penal de las personas jurídicas: el papel del juez ante el peligro de hipertrofia de las compliance", Estudios Penales y Criminológicos, XXXV (2015), 919-963. 
diferenciados para la aplicación de la eximente, dependiendo de quién haya realizado el delito (hecho de conexión): i) si son miembros están autorizados en tomar decisiones a nombre de la persona jurídica u ostentan facultades de organización y control dentro de ella; o ii) si se trata de empleados que se encuentran bajo la vigilancia de los primeros. No obstante, el fundamento último de ambos supuestos es la ausencia de un "debido control" ${ }^{26}$ relacionado a un "defecto de organización" que excluye la culpabilidad empresarial27.

Los efectos eximentes del compliance por delitos cometidos por los directivos o representantes de la empresa, es el supuesto que genera mayor crítica. Existen autores que señalan que el compliance no tendría eficacia para delitos dolosos cometidos por representantes, pues, ante la resolución criminal de cometer determinados delitos por estos sujetos, los controles preventivos no serían obstáculo suficiente28. Por ello, se sostiene que el directivo o representante siempre vincularía automáticamente con su accionar delictivo a la persona jurídica, convirtiéndola a ella misma también en autora del delito; es decir, se estaría ante un sistema de responsabilidad vicarial de la persona jurídica en estos casos. Así, el compliance sería a priori irrelevante para eximir de responsabilidad a la persona jurídica cuando el delito es cometido por alguno de sus directivos o representantes.

Sobre esta problemática, se dan tres posibles soluciones: i) admitir el efecto eximente del compliance para todos los casos cuando los delitos los comentan representantes, sean dolosos 0 imprudentes; ii) limitar la eficacia eximente del compliance solo a casos en los que la actuación delictiva de los representantes se considere desviada de la voluntad social favorable al cumplimiento de las normas penales; y iii) restringir la eficacia eximente de los compliance a los delitos imprudentes29. En nuestra opinión, debe seguirse la segunda opción, ya que los programas de cumplimiento adecuadamente implementados sí pueden evidenciar una cultura de cumplimiento penal empresarial en algunos casos. No se puede rechazar siempre la eficacia de los efectos eximentes del compliance por el solo hecho de verificar que el delito lo cometió un representante o directivo de la empresa.

26 E. Bacigalupo Zapater. Compliance y Derecho Penal, (Pamplona: Aranzadi, 2011), 82.

27 J.M. Zugaldía Espinar. La responsabilidad criminal de las personas jurídicas en el derecho penal español (análisis de la cuestión tras la reforma operada por la LO 1/2015, de 30 de marzo), (Madrid: Editorial Universitaria Ramon Areces, 2016), 236-237.

28 M. Cugat Mauri. "La reforma de la responsabilidad penal de las personas jurídicas: el papel del juez ante el peligro de hipertrofia de las compliance", 939

29 Ibid., 945. 
En el caso de la legislación española, el artículo 31bis del CP establece que, para que pueda tener efecto eximente de responsabilidad penal de la persona jurídica, el compliance debe tener elementos obligatorios ${ }^{30}$. Por un lado, se exige no solo que se apruebe un programa de cumplimiento, sino que este haya sido adoptado y ejecutado con eficacia, por lo que se reduce significativamente el riesgo de los famosos "compliance fachada" que solo buscan la impunidad de la organización sin prevención. También, implementar medidas de vigilancia y control "idóneas para prevenir delitos de la misma naturaleza o para reducir de forma significativa el riesgo de su comisión". Aunque la evaluación es tarea de los operadores de justicia, la legislación deja en claro que no bastará con un compliance formal, sino uno material que despliegue verdaderos efectos preventivos de la criminalidad empresarial, ex ante $e^{31}$.

Por otro lado, si se trata de delitos cometidos por subordinados (empleados) de la persona jurídica las exigencias de la regulación española son menores. Se debe haber "adoptado y ejecutado eficazmente un modelo de organización y gestión que resulte adecuado para prevenir delitos de la naturaleza del que fue cometido o para reducir de forma significativa el riesgo de su comisión". La diferencia de lo sucedido cuando el delito lo cometía un directivo es la no obligatoriedad de medidas de vigilancia y control idóneas. Por otro lado, en este último supuesto, no se exige para aplicar la eximente que se haya eludido fraudulentamente el compliance ni que se haya implementado una oficina de cumplimiento normativo (compliance officer). La flexibilización para aplicar la eximente es razonable en el último caso debido a que no representarían la "voluntad" de la persona jurídica. Aunque ello no quiere decir que baste con la aprobación formal de compliance, pues, como lo señala la propia norma, este modelo de prevención debe ser adoptado y sobre todo ejecutado eficazmente en la empresa para que despliegue sus efectos eximentes. Tomando en consideración que en ambos casos el fundamento de la sanción o no de la persona

30 1. El órgano de administración ha adoptado y ejecutado con eficacia, antes de la comisión del delito, modelos de organización y gestión que incluyen las medidas de vigilancia y control idóneas para prevenir delitos de la misma naturaleza o para reducir de forma significativa el riesgo de su comisión; 2. la supervisión del funcionamiento y del cumplimiento del modelo de prevención implantado ha sido confiada a un órgano de la persona jurídica con poderes autónomos de iniciativa y de control o que tenga encomendada legalmente la función de supervisar la eficacia de los controles internos de la persona jurídica;

3. Ios autores individuales han cometido el delito eludiendo fraudulentamente los modelos de organización y de prevención y

4. no se ha producido una omisión o un ejercicio insuficiente de sus funciones de supervisión, vigilancia y control por parte del órgano al que se refiere la condición 2.

31 J.M. Silva Sánchez. Fundamentos del Derecho penal de la empresa, (Barcelona: Edisofer, 2013), 197. 
jurídica es el debido control, por lo que igual se deberá evaluar concretamente la implementación adecuada de medidas de vigilancia y control.

Al respecto, en ambos casos (delitos cometidos por directivos y empleados subordinados) se debe realizar una verificación exhaustiva de la idoneidad del programa de cumplimiento para prevenir la infracción de normas penales; labor de dos etapas ${ }^{32}$ :

i. Evaluación abstracta: verificar que desde la dirección de la empresa se han hecho esfuerzos serios de crear una cultura de legalidad y establecer controles apropiados. Si este filtro no se supera, la sanción es más gravosa debido al alto grado de culpabilidad de la empresa al no crear las herramientas esenciales de gestión

ii. Evaluación concreta: evalúa la existencia de medidas o mecanismos de detección e investigación para hechos similares a los producidos y examina por qué fallaron en el caso concreto.

De esta manera, siguiendo a Nieto, el "test del debido control" que se debe llevar a cabo para evaluar la culpabilidad penal de la persona jurídica consistirá en lo siguiente: i) previsibilidad del delito, en el cual se evalúe los riesgos penales de la actividad empresarial, ii) eficacia de los controles ex ante, en el cual se evalúe la eficacia de los elementos básicos del compliance (se deberá tomar en cuenta como criterios de calidad la implicación de los directivos, la participación de los trabajadores, independencia y formación de los responsables de cumplimiento, etc.), así como la eficacia de los controles específicos para prevenir hechos similares a los que se han producido; iii) eficacia de los controles ex post, en los casos donde a pesar que la empresa no ha superado el análisis ex ante, tiene controles que han dificultado notablemente la comisión del delito o favoreciendo su descubrimiento ${ }^{33}$.

Asimismo, hay que notar que por más que el programa de cumplimiento esté aprobado previamente por una autoridad estatal o por un organismo especializado externo, son los propios operadores de justicia quienes finalmente decidirán si el compliance fue idóneo o no para el caso concreto. Lo resuelto por la entidad supervisora o la empresa no es vinculante, sino solo un indicio probatorio que se

32 Nieto Martin. "Responsabilidad social, gobierno corporativo y autorregulación: sus influencias en el derecho penal de la empresa", 39.

33 Nieto Martín. "Lección II. Cumplimiento normativo, criminología y responsabilidad penal de personas jurídicas", 50 y ss. 
puede utilizar en la evaluación ${ }^{34}$. Al respecto, la evaluación de la adecuación de los programas de cumplimiento en las organizaciones no es sencilla, pero debe evitarse caer en excesos de punición o casos de impunidad. Los compliance deberán ser considerados como un criterio importante a tomar en cuenta para verificar el "defecto de organización" en la empresa, pero este criterio no es exclusivo de otros que se deban analizar en el caso concreto.

\section{Criminal compliance y responsabilidad penal individual}

La implementación de los compliance programs también incide en la determinación de la responsabilidad de las personas individuales que cometen delitos al interior de una organización empresaria| ${ }^{35}$. Este mecanismo se usaría como un criterio importante, pero no único, para evaluar la responsabilidad penal de los miembros de la organización.

El aporte principal y objetivo del compliance es coadyuvar eficazmente a la prevención de la criminalidad individual en el marco de la actividad empresarial. Sin embargo, si el mecanismo es solo formal y no se adecua materialmente a prevenir los riesgos penales, no sería considerado un elemento a evaluar en la responsabilidad individual.

En primer lugar, los programas de cumplimiento tienen especial relevancia para evaluar el riesgo permitido y la aplicación del principio de confianza en un caso concreto. En efecto, las conductas toleradas en la práctica social o permitidas normativamente se sostiene que se encuentran en el marco de un "riesgo permitido" para el derecho pena ${ }^{36}$. Por su parte, el principio de confianza es una figura jurídica que excluye la imputación objetiva de la conducta cuando el sujeto que realiza una actividad arriesgada puede confiar en el comportamiento correcto de los que participan junto a él en dicha actividad, mientras no existan indicios que ello no va a ser así. Este principio tiene una operatividad e importancia práctica en aquellas actividades colectivas en las que existe una división de funciones jerarquizadas, donde los sujetos intervinientes se verán obligados conjuntamente a controlar un determinado aspecto del riesgo. En estos casos, el superior jerárquico cuenta con

34 García Cavero, 152-153.

35 Así lo considera también Silva Sánchez, 197 y ss; y Nieto Martín, “Lección II. Cumplimiento normativo, criminología y responsabilidad penal de personas jurídicas", 64 y ss.

36 M. Cancio Melia. "Aproximación a la teoría de la imputación objetiva". En Cuestiones actuales de derecho penal económico. (Madrid: Colex, 2008), 45-46. 
ciertos deberes de garante sobre la conducta de sus subordinados, como deberes de selección, instrucción, control y supervisión ${ }^{37}$.

Los programas de cumplimiento (compliance programs) de las organizaciones constituyen un cuerpo normativo interno no estatal sin capacidad de determinar el riesgo permitido para la actividad empresarial, pero si en cierto rubro de actividades empresariales se logra estandarizar y masificar procedimientos, se puede llegar a establecer una lex artis que determine el riesgo permitido penal ${ }^{38}$. Un ejemplo de ello pueden ser los ISO certificados en un rubro de actividad empresarial que servirían como un parámetro de conducta para analizar la corrección o no de la actividad empresarial de cara a una eventual sanción penal. Aunque ello requiere se expandan y practiquen en muchas organizaciones. Es preciso recalcar que un compliance program aislado en una sola empresa no puede determinar por sí solo el riesgo permitido penal, sino que deberá tratarse de estándares extendidos en una pluralidad de empresas y validados por la práctica empresarial y/o estándares internacionales de calidad.

Asimismo, como se dijo, estos programas pueden servir también para evaluar la aplicación del principio de confianza en la criminalidad empresarial, pues en la gestión empresarial rige el "principio de desconfianza" en relación con la división del trabajo vertical y la delimitación de competencias ${ }^{39}$, pero con un compliance ex ante el principio citado puede variar por el "principio de confianza" en base al mecanismo de compliance correctamente implementado. Si esto es así, los superiores jerárquicos podrán confiar en que sus subordinados no cometerán delitos, salvo que en el caso concreto adviertan indicios serios de lo contrario, toda vez que los programas establecen las competencias de cada uno de los cargos dentro de la empresa y obligaciones de los superiores respecto de los inferiores jerárquicos, mejorando la dinámica de delegaciones al interior. La correcta delegación de funciones modifica la posición jurídica del delegante (directivo), liberándolo parcialmente de sus deberes de competencia, a excepción de la supervisión ${ }^{40}$.

37 M. Maraver Gomez. "El principio de confianza en Derecho Penal". En Derecho Penal del Estado Social y Democrático de Derecho, coordinado por M. Luzon Peña, (Madrid: La Ley, 2010), 400.

38 COCA VILA, 66.

39 FeıJóo Sánchez. "Autorregulación y Derecho penal de la empresa: ¿una cuestión de responsabilidad individual?", 247.

40 Balcarce y Berruezo, 166 y 172 
150 Repercusiones jurídico-penales del criminal compliance. A propósito de la

regulación española - Rafael H. Chanjan Documet,

Otra institución ligada al compliance es la posición garante que asumen los superiores jerárquicos. Pues, en la criminalidad de empresa es fundamental investigar a los mandos altos y medios, más allá de los integrantes de la base de la organización. Por lo tanto, es importante analizar la posición de garante de los directivos de la organización en la ejecución de actos criminales, lo cual podría ser penalmente relevante si se imputa un delito de tipo omisivo.

La teoría de la conducta omisiva (comisión por omisión u omisión impropia) surge para solucionar la problemática de la responsabilidad de los superiores jerárquicos y los ilícitos de sus subordinados. Los superiores jerárquicos asumirían voluntariamente una posición de garante, un deber de control de los hechos con relevancia penal que se susciten en la empresa por la conducta de sus subordinados como fuentes de riesgo. El empresario adquiere competencia para contener los riesgos de su actividad empresarial a través de la vigilancia y la adopción de medidas que eviten la vulneración de bienes jurídicos. Aunque ello no significa que el empresario va a responder por todos los delitos cometidos por sus subordinados, sino sólo por los delitos vinculados al giro del negocio o las actividades habituales de la organización ${ }^{41}$.

Al respecto, la relación del compliance y el deber de vigilancia jurídico-penal de los directivos es una relación de género-especie, porque los objetivos y ámbito de acción de los programas trascienden al mero control o vigilancia empresarial. También porque de un programa compliance no se infiere automáticamente el cumplimiento del deber jurídico de vigilancia por parte de los directivos. No obstante, se reconoce que la adopción e implementación de los compliance sirven para formalizar y sistematizar las medidas de vigilancia sobre subordinados ${ }^{42}$. De esta manera, el compliance program correctamente implementado permite la optimización de las posiciones de garantía en la empresa, explicitando los deberes inherentes al cargo o delimitándolos expresamente. En los casos de delegación de competencias de los directivos hacia otros mandos intermedios u empleados, los deberes de control del superior jerárquico, luego de la delegación, se transforman en una responsabilidad en la vigilancia de las actividades del delegado, supervisión, coordinación y la correcta elección ${ }^{43}$.

\footnotetext{
41 Silva Sánchez, 86.

42 Ibid., 193-194.

43 Feijóo Sánchez, 244.
} 
Cabe notar que los compliance programs pueden hacer surgir responsabilidades en los oficiales de cumplimiento (compliance officer) delegados ${ }^{44}$, quienes tendrán el deber principal de prevenir delitos dentro de la empresa, y transformar los deberes de garante de los directivos en deberes de vigilancia y supervisión del oficial de cumplimiento. Los programas sirven para plasmar formalmente los procedimientos y contenidos de la delegación de funciones en cuanto a supervisión de inferiores jerárquicos en la empresa, son útiles para documentar lo que surge de la relación de subordinación o delegación; define las tareas de cada persona en la cadena de mando organizacional y el flujo de información entre los cargos.

Por otro lado, el programa de cumplimiento también puede incidir en la determinación de la imputación subjetiva de la conducta de los miembros de una organización. Es importante la evaluación del dolo en la actuación u omisión de los superiores jerárquicos respecto de la actuación de sus empleados, ya que en ocasiones conocen el acto de la probabilidad del acto ilícito en el giro de la empresa, pero deciden ignorarlo (ignorancia deliberada) ${ }^{45}$. Por lo tanto, es importante implementar una cultura de legalidad en la empresa, con una adecuada gestión de los flujos de información entre superiores e inferiores jerárquicos de cara a que se produzca una correcta labor de supervisión y control interno. Los compliance programs permitirían saber si el superior jerárquico conoció o pudo conocer suficientemente 0 se representó como probable el riesgo penalmente prohibido que generó el empleado. Lo mismo podría decirse respecto de la determinación del dolo en los operarios o empleados, pues si fueron instruidos previamente en las acciones prohibidas en el giro del negocio es más complicado argumentar una no representación o no conocimiento suficiente del riesgo penal creado.

Por último, el compliance program sería útil también para determinar la infracción del deber objetivo de cuidado en los delitos imprudentes ${ }^{46}$. En efecto, en los delitos imprudentes se requiere la comprobación de la infracción de un deber objetivo de cuidado, por lo que en el programa de cumplimiento organizacional pueden plasmarse los parámetros de actuación diligente de los superiores jerárquicos respecto de la supervisión y control de las distintas áreas de la actividad empresarial. Además, el programa sería un criterio para evaluar la existencia de un error de tipo (vencible 0 invencible) del empleado cuando interviene o ejecuta materialmente un delito.

44 Silva Sánchez, 199.

45 Nieto Martin. “Lección II. Cumplimiento normativo, criminología y responsabilidad penal de personas jurídicas", 55.

46 COCA VILA, 66 
La implementación, difusión y capacitación del contenido normativo del programa de cumplimiento será un factor relevante para conocer si el empleado estuvo en condiciones de reconocer que su conducta creaba un riesgo penalmente prohibido y configuraba un delito de corrupción, por ejemplo. Ante la instrucción previa del programa de cumplimiento a todos los miembros de una empresa es difícil sostener la actuación bajo error invencible.

\section{Conclusión}

El compliance, en tanto forma de manifestación de una autorregulación regulada y fomentada, pretende coadyuvar a las estrategias político-criminales del Estado de lucha contra la criminalidad, en especial, la criminalidad empresarial. De esta manera, los programas de cumplimiento penal o criminal compliance buscan prevenir la comisión de delitos en el seno de la empresa, así como detectar, investigar y reportar los actos ilícitos que se cometan a fin de generar dentro de la empresa una cultura de legalidad con el Derecho Penal.

El paradigma del criminal compliance en el ámbito empresarial tiene repercusiones importantes en la determinación de la responsabilidad penal de las propias personas jurídicas y de las personas individuales. En el caso específico de la responsabilidad penal de las personas jurídicas, los compliance han sido contemplados como eximentes de responsabilidad, siempre que se realice una debida verificación concreta y abstracta que determine su idoneidad para la prevención delictiva. Asimismo, el criminal compliance, respecto de la responsabilidad penal individual, puede servir para evaluar el riesgo permitido, el principio de confianza, la posición de garante y la imputación subjetiva de la conducta de los miembros de la organización.

\section{Bibliografía}

ArRoyo Jimenez, L. "Introducción a la autorregulación", En Autorregulación y sanciones, coordinado por L. Arroyo Jimenez y A. Nieto Martin, 19-35. Navarra: Aranzadi, 2015.

Bacigalupo Zapater, E. Compliance y Derecho Penal, Pamplona: Aranzadi, 2011.

Balcarce, F. y Rafael Berruezo. Criminal compliance y personas jurídicas. Montevideo: BdeF, 2016.

Bock, D. "Compliance y deberes de vigilancia en la empresa". En Compliance y teoría del Derecho Penal, coordinado por J.P Montiel, L. Kuhlen e I. Ortiz De Urbina Gimeno, 107-122. Madrid: Marcial Pons, Madrid, 2013. 
Cancio melí, M. "Aproximación a la teoría de la imputación objetiva". En Cuestiones actuales de derecho penal económico. Madrid: Colex, 2008.

Caro Coria, D. C. y L.M Reyna Alfaro. Derecho Penal económico. Parte General. Tomo I. Lima: Jurista Editores, 2016.

Coca VILA, I. "¿Programas de cumplimiento como forma de autorregulación regulada?" En Criminalidad de empresa y compliance, coordinado por J.M. Silva Sánchez, 43.73. Barcelona: Atelier, 2013.

Cugat Mauni, M. "La reforma de la responsabilidad penal de las personas jurídicas: el papel del juez ante el peligro de hipertrofia de las compliance", Estudios Penales y Criminológicos, XXXV, (2015): 919-963.

DarnaCulleta I Gardella, M. "La autorregulación regulada en la doctrina anglosajona y continental-europea". En Autorregulación y sanciones, coordinado por L. Arroyo Jimenez y A. Nieto Martin, 119-145. Navarra: Aranzadi, 2015.

FelJoo SÁnchez, B. "Autorregulación y Derecho penal de la empresa: ¿una cuestión de responsabilidad individual?". En Autorregulación y sanciones, coordinado por L. Arroyo Jimenez y A. Nieto Martin, 200-252. Navarra: Aranzadi, 2015.

García Cavero, P. Criminal compliance. En especial compliance anticorrupción y antilavado de activos. Lima: Instituto Pacífico, 2017.

Gómez-JARA Díez, C. "La incidencia de la autorregulación en el debate legislativo y doctrinal actual sobre la responsabilidad penal de las personas jurídicas". En Autorregulación y sanciones, coordinado por L. Arroyo Jimenez y A. Nieto Martin, 253-313. Navarra: Aranzadi, 2015.

Kunlen, L. "Compliance y Derecho penal en Alemania", En Responsabilidad de la empresa y compliance, coordinado por S. Mir Puig, M. Corcoy Bidasolo y V. Gómez Martín, 89-126. Madrid: Edisofer, 2014.

Maraver Gomez, M. "El principio de confianza en Derecho Penal". En Derecho Penal del Estado Social y Democrático de Derecho, coordinado por M. Luzon Peña. Madrid: La Ley, 2010.

Nieto Martín, A. "Lección II. Cumplimiento normativo, criminología y responsabilidad penal de personas jurídicas", En: Manual de cumplimiento penal. Nieto Martín, A. (Director). Tirant lo blanch, Valencia, 2015

Nieto Martín, A. "Responsabilidad social, gobierno corporativo y autorregulación: sus influencias en el derecho penal de la empresa", Política Criminal, $n^{\circ} 5$ (2008): 3-5, 1-18.

Rotsch T., "Criminal compliance". Indret, 1/2012 (2012): 1-12. 
154 Repercusiones jurídico-penales del criminal compliance. A propósito de la regulación española - Rafael H. Chanjan Documet,

Silva SÁnchez, J. M. Fundamentos del Derecho penal de la empresa. Barcelona: Edisofer, 2013.

Zugaldía Espinar, J. M. "La responsabilidad criminal de las personas jurídicas en el derecho penal español (análisis de la cuestión tras la reforma operada por la L0 1/2015, de 30 de marzo)". En Estudios de Derecho Penal, coordinado por S. Bacigalupo, B. Feijoo Sánchez y J. Echano Basualda, 693-714. Madrid: Editorial Universitaria Ramon Areces, 2016. 